\title{
PERBANDINGAN UNJUK KERJA KOMPOR METHANOL DENGAN VARIASI DIAMETER BURNER
}

\author{
Subroto \\ Program Studi Teknik Mesin, Fakultas Teknik, \\ Universitas Muhammadiyah Surakarta \\ J1.A. Yani Tromol Pos 1 Pabelan, Kartasura \\ E-mail: subroto.ums@gmailicom
}

\begin{abstract}
ABSTRAK
Sampai saat ini sebagian masyarakat masih banyak menggunakan mimyak tanah sebagai bahan bakar untuk keperluan rumah tangga maupun industri, walaupun harga minyak tonah naik cukup tinggi kanena subsidi dari pemerintah dicabut. Untuk mengurangi ketergantungan minyak tanah perlu penggumaan bahan bakar aiternatifyaitu methanol. Methanol mempunyat kelebihan mudah didapatkan ditapangan dan dengan harga yang lebih murah dari minyak tanah. Kompor methanol sudah dikenal masyarakat akan tefapi penggunaanya masih sangat terbatas karena unjuk kerjanya masih kurang baik dibandingkan kompor minyak tanah. Penelitian ini bertujuan untuk mengetahut unjuk kerja kompor methanol melalui pengaruh variasi diameter burner.

Penelitian dimulai dengan rancang bangun burner terbuat dari bahan kuningan dengan tiga macam model dengan variasi diameter bumer dan tinggi bumer maupun jumlah lubang tetap. Pengujian unjuk kerja berdasarkan karakteristik pembakaran dilakukan melalwi water boiling test. Parameter yang diukur meliputi temperatur api pembakaran, temperatur air, konsumsi bahan bakar, dan waktu pendidihan.

Hasil penelitian menunjukkan bahwa variasi diameter burner berpengaruh terhadap karakteristik pembakaran yang dihasilkan. Temperatur pembakaran yang tinggi dicapai oleh burner dengan diameter $12,8 \mathrm{~mm}$ dan $10 \mathrm{~mm}$, konsumst bahan bakar yang kecil burner diameter $12,8 \mathrm{~mm}$ dan waktu pendidihan yang pendek dicapai burner $12,8 \mathrm{~mm}$. Jadi kompor methanol dengan unjuk kerja terbaik adalah kompor methanol dengan diameter burner $12,8 \mathrm{~mm}$
\end{abstract}

Kata Kunci : Kompor, methanol, burner, diameter, unjuk kerja.

\section{PENDAHULUAN}

Bahan bakar tetah menjadi kebutuhan yang tidak dapat terlepaskan dari kehidupan seharihari saat ini, Mulai dari kebutuhan rumah tangga, transportasi dan bertbagai macam kebutuhan lainnya tidak dapat teriepas dari penggunaan bahan bakar, terutama bahan bakar minyak. Seiring dengan terus meningkatnya kebutuhan akan bahan bakar minyak fosil membuar semakin menipisnya ketersediaan bahan bakar minyak tersebut, disisi lain seperti yang kita tahu bahwa bahan bakat fosil merupakan sumber energi yang tidak terbaharukan, Methanol diharapkan dapat menjadi salah satu solusi sebagai bahan bakar altematif untuk membantu mengurangi masalah-masalah tersebut dengan berbagai macam cara, salah satunya dengan meningkatkan effisiensi pem- 
bakaran methanol. Bagi iburumah tangga maupun industri kecil seperti industri batik untuk pemanasun lilin batik, hal ini merupakan menupakan salah satu altermatif untuk mengatasi ketergantungan khususnya minyak tanah dan juga sebagai salah satu solusi untuk menekan biaya produksi pada industri batik. Seperti yang kita talu bahwa saat ini permintaan akan batik semakin meningkat seiring dengan penetapan batik sebagai warisan budaya dunia dari indonesia olch UNESCO. Dalam hal peningkatan effisiensi pembakaran bahan bakar pasti tidak akan terlepas dari desain burner sehingga panas yang dihasilkan tidak banyak terbuang dan konsumsi bahan bakar menjadi lebih hemat.

\section{Tinjauan Pustaka}

Lembaga Penelitian dan Pengabdian Kepada Masyarakat ITS (2009) telah melakukan pengujian terhadap kompor bioetharol, ditemukan bahwa efisiensi kompor bioethanol sebesar 54 persen. Sementara kompor kerosin atau minyak tanah hanya 49 persen. Dari pengkajian sampel bioethanol di laboratorium Jurusan Kimia ITS, didapatkan hasil bahwa kalor adalah 5270 $\mathrm{kKal} / \mathrm{kg}$. Dibandingkan dengan kalor kerosin, ini haryya sekitar sepanuhnya.

Oky Norli S (2007) melakukan penelitian tentang pengaruh bentuk, penambahan reflektor dengan tekanan bahan bakar terhadap temperatur api yarg dihasilkan pada kompor minyak tanah bertekanan yang menyatakan bahwa dari perbandingan masing-masing kompor dengan kondisi terbaiknya, kondisi optimal dihasilkan oleh kompor dengan menggunakan reflektor bulat pada tekanan $0.2 \mathrm{MPs}$.

Kerampran et all. (2000) dalam perelitiannya mengenai masalah mekanisme perambatan api di dalam tube menyatakan bahwa pergerakan api yang berimbas pada distribusi temperatur dipengaruhi oleh dimensi burner.

Hase et all. (1991) dalam penelitiannya mengenai masalah pengaruh $\mathrm{AF}$ ratio terhadap pembakaran gas dalam burner dengan lobang burner sejumlah 3 buah dan bersudut masingmasing $60^{\prime \prime}$ mengungkapkan bahwa AF ratio

memiliki efek terhadap temperatur pembakaran yang dihasilkan dan letak temperatur maksimal dalam burner.

Subroto dkk (2009) melakukan penelitian peningkatan kualitas pembakaran tungku briket batubara yang ramah lingkungan untuk aplikasi rumah tangga menyatakan bahwa penambahan kecepatan udara pembakar mempengaruhi karakteristik pembakaran yang ditunjukkan oleh temperatur dan kadar polutan hasil pembakaran.

\section{Kalor Pembakaran}

Nilai kalor yaitu kalor yang dihasilkan dari pembakaran sempurna 1 satuan berat bahan bakar padat atau bahan bakar cair atau 1 satuan volume bahan bakar gas pada kondisi baku (tekanan 1 atm, suhu $25^{\circ} \mathrm{C}$ atau $60^{\circ} \mathrm{F}$ ) Nilai kalor atau heating vahue dapat dibagi menjadi dua macam yaitu: HHV (Higher Heating Value) dan LHV (Lower Heating Value)

\section{Methanol}

Mctanol merupakan salah satu jenis bahan bakar cair yang saat ini mulai diminati untuk dijadikan sebagai bahan bakar alternatif penggunti minyak bumi dalam skala kecil dan menengah. Metanol juga dikenal sebagai metil alcohol atau wood alcohol dengan rumus kimia $\mathrm{CH}_{3} \mathrm{OH}$. Metanol memiliki sifat-sifat antan lain :

1. Rumus Molekul

2. Berat Molekul

3. Massa jenis

4. Titik Beku

5. TitikNyala

6. Temperatur Penyalaan

7. Titik Didih

8. HHV atau $22,7 \mathrm{KJ} / \mathrm{g} \mathrm{LHV}: 638 \mathrm{KJ} / \mathrm{mol}$ atau $19,9 \mathrm{KJ} / \mathrm{g}$

Reaksi kimia methanol yang terbakar di udara dan membentuk karbon dioksida dan air adalah sebagai berikut: $2 \mathrm{CH}_{3} \mathrm{OH}+3 \mathrm{O}_{2} " 2 \mathrm{CO}_{2}$ $+4 \mathrm{H}_{2} \mathrm{O}$ ). 


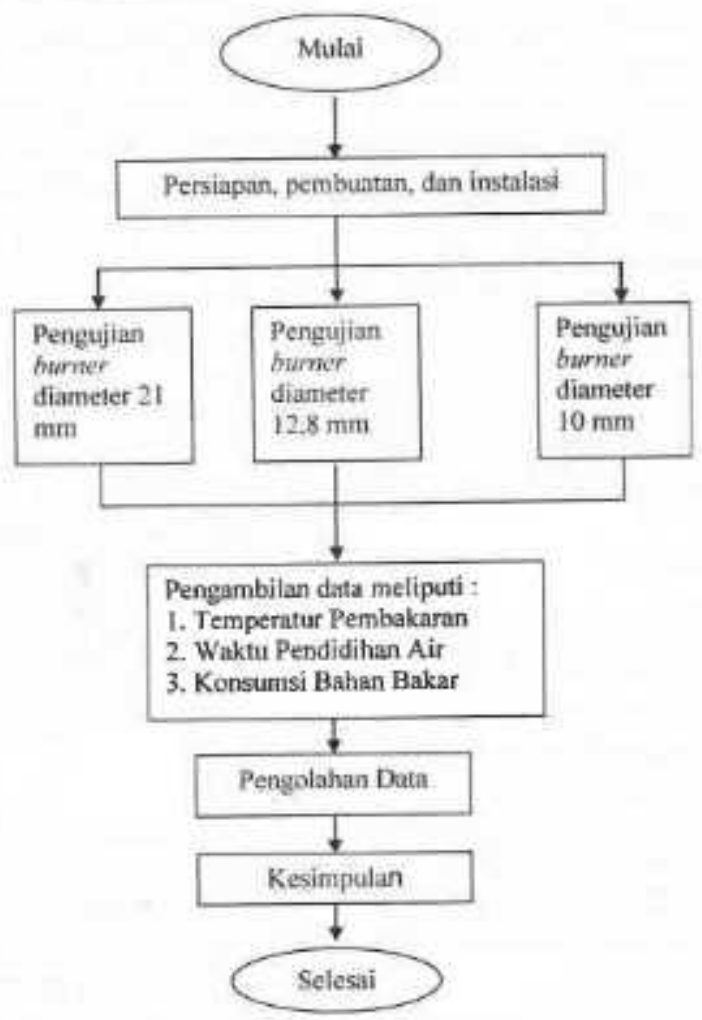

Gambar 1. Diagram Aliran Penelitian

\section{Instalasi Pengujian}

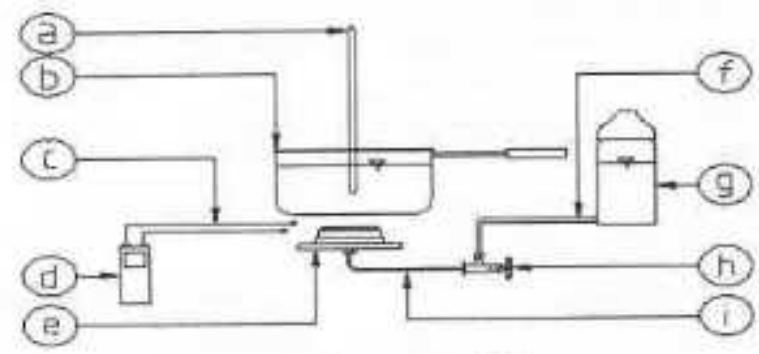

Gambar 2. Skema Penelitian

Keterangan :

a. Thermometer

b. Panci

c. Thermocouple

d. Thermocouple reader c. Burner diameter $21 \mathrm{~mm}, 12.8 \mathrm{~mm}$ dan $10 \mathrm{~mm}$

f. Selang Bahan Bakar

g. Tabung Bahan Bakar

h. Katup pengatur aliran bahan bakar

i. Pipa tembaga 
Jalannya penelitian :

1. Pengambilan data benupa temperatur api, waktu pendidihan air, dan konsumsi buhan bakar.

2. Temperatur api diukur menggunakan Thermocouple dan Thermocouple Reader yang ditempatkan pada burner sebanyak empat titik dengan ketinggian yang sama.
3. Waktu pendidihan air diukur dengan stopwatch dan dicatat tiap menit selama 15 menit. Untuk kenaikan temperatur air diukur dengan thernometer.

4. Konsumsi bahan bakarjuga dicatat tiap menit, banyaknya bahan bakar yang digunakan dapat dilihat pada tabung bahan bakar.

\section{HASIL DAN PEMBAHASAN}

\section{Temperatur Pembakaran}

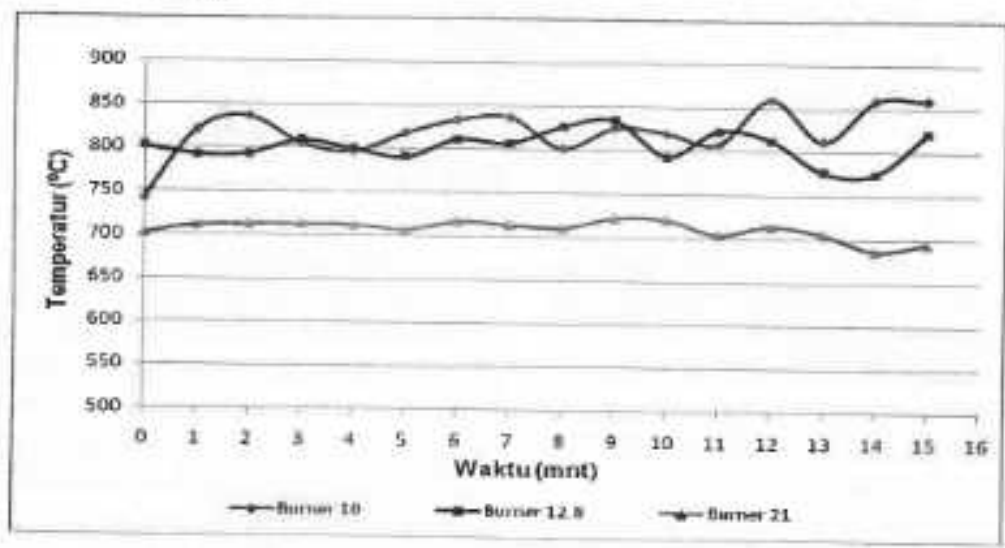

Gambar 3.Perbandingan temperatur pembakaran burner diameter $21 \mathrm{~mm}, 12,8 \mathrm{~mm}, 10 \mathrm{~mm}$

\section{Waktu Pendidihan Air}

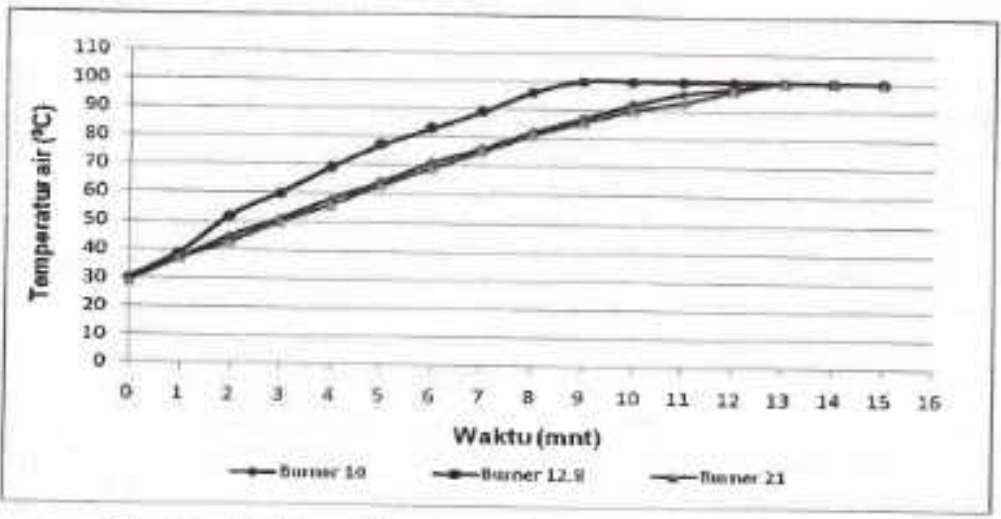

Gambar 4. Perbandingan temperatur air pendidihan burner diameter $21 \mathrm{~mm}, 12,8 \mathrm{~mm}, 10 \mathrm{~mm}$ 


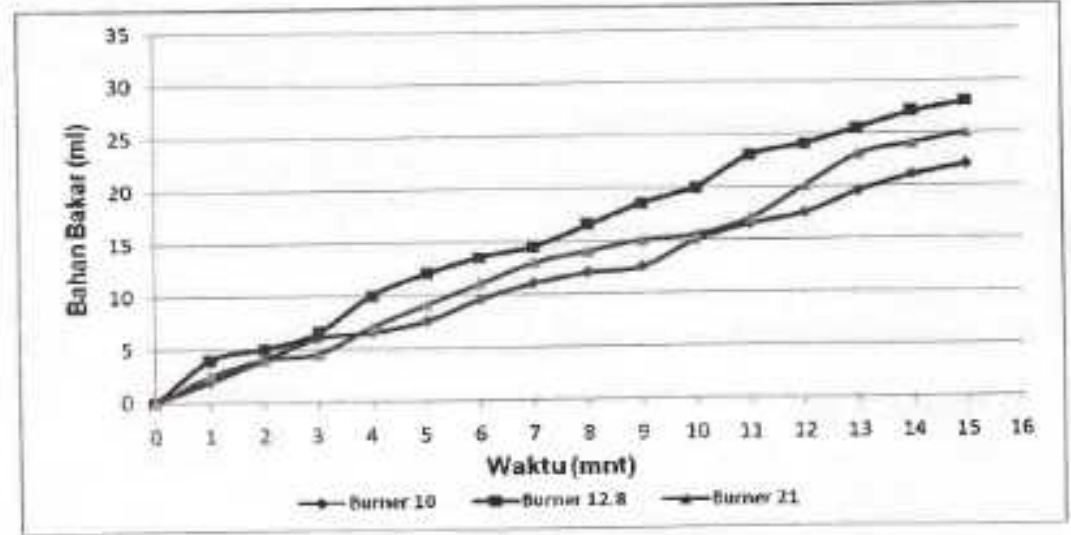
Gambar 5. Perbandingan konsumsi bahan bakar burner
diameter $21 \mathrm{~mm}, 12,8 \mathrm{~mm}$ dan $10 \mathrm{~mm}$

Dari gambar 3 dapat dilihat setiap burner memiliki ternperatur pembakaran yang berbeda. Pada bumer dengan diameter $21 \mathrm{~mm}$ temperatur terlihat lebih stabil dibanding dengan bumer lain akan tetapitemperatur yang dihasilkan relatif lebih rendah dari burner lain yaitu $705^{\circ} \mathrm{C}$. Sedangkan pada bumer diameter $12,8 \mathrm{~mm}$ temperatur api cenderung lebih stabil pada awal pembakaran dan sedikit kurang stabil pada akhir pembakaran tetapi temperatur yang dihasilkan cukup tinggi dengan temperatur rata-rata 810 ${ }^{\circ} \mathrm{C}$.

Dari hasil pengujian pendidihan air yang ditumjukkan gambar 4 dapat kita lihat secara jelas bumer $12,8 \mathrm{~mm}$ merupakan bumer yang paling cepat mendidihkan $500 \mathrm{ml}$ air dengan waktu 9 menit. Sedangkan pada burner diameter $10 \mathrm{~mm}$ dan 21 mm memertukan waktu yang sama untuk mengubah temperatur air hingga mencapai titik didihnya yaitu 13 menit. Pada burner dengan diameter $10 \mathrm{~mm}$ temperatur terlihat tidak stabil dari awal dan akhir pembakaran hanya pada menit ke-2 hingga ke-11 menunjukan emperatur yang lebih baik. Hal ini menjadi salah satu sebab lamanya waktu pendidihan air pada burner dengan diameter $10 \mathrm{~mm}$ meskipun temperatur yang dihasilkan cukup tinggi yaitu berada pada kisaran $825^{\circ} \mathrm{C}$
Konsumsi bahan bakar selama 15 menit ditujukkan pada gambar 5 pada bumer diameter $12,8 \mathrm{~mm}$ dalam grafik terlihat lebih besar jika dibanding dengan burner lain. Akan tetapi jika dilihat dari waktu pendidihan air dan konsumsi bahan bakar burner dengan diameter $12,8 \mathrm{me}$ rupakan bumer yang lebih baik karena lebith cepat untuk mendidihkan air. Hal ini dapat diketahui dengan cara membandingkan konsumsi bahan bakar dan lamanya waktu yang diperlukan untuk mendidihkan $500 \mathrm{ml}$ air. Pada burner $21 \mathrm{~mm}$ waktu yang diperlukan untuk menaikkan temperatur air hingga mencapai titk didih adalah 13 menit dengan konsumsi bahan bakar sebanyak $23 \mathrm{ml}$, sedangkan pada burner $12,8 \mathrm{~mm}$ waktu yang dipertukan relatif cepat yaitu 9 menit dengan konsumsi bahan bakar $18,5 \mathrm{mi}$ dan pada bumer dengan diameter $10 \mathrm{~mm}$ waktu yang diperlukan untuk meningkatkan temperatur air adalah 13 menit dengan konsumsi bahan bakar $19,5 \mathrm{ml}$.

Pada gambar 4 menunjukkan bahwa burner dengan diameter 12,8 lebih cepat menaikkan temperatur air hingga mencapai titik didih dan memerlukan bahan bakar yang sedikit dibanding dengan burner lainnya sehingga dapat disimpulkan burner dengan diameter 12,8 lebih efektif jika dibanding dengan bumer lainnya pada penelitian ini. 
Effisiensi Pembakaran pada Burner

Tabel 1. Perbandingan antara Kalor Metanol dengan Kalor untuk mendidihkan Air

\begin{tabular}{|c|c|c|c|}
\hline $\begin{array}{c}\text { Diameter } \\
\text { Burner (mm) }\end{array}$ & Qair $_{\text {(K.J) }}$ & $\mathrm{Q}_{\text {вв }}(\mathrm{KJ})$ & ๆ (\%) \\
\hline 21 & 143,65 & 413,82 & 35,22 \\
\hline 12,8 & 143,65 & 333,96 & 43,01 \\
\hline 10 & 143,65 & 348,48 & 41,22 \\
\hline
\end{tabular}

Perhitungan effisiensi pada burner dapat diperoleh dengan cara membandingkan antara kalor yang dilepaskan oleh bahan bakar dengan kalor yang dibutuhkan untuk mendidihkan air. Dari hasil perhitungan kalor maka didapatkan hasil seperti pada Tabel 1. Dari hasil perhitungan kalor yang dihasilkan oleh bahan bakar dan kalor yang diserap air hingga mencapai titik didihnya maka diperoleh prestasi dari masing-masing bur ner. Burner dengan diameter $12,8 \mathrm{~mm}$ merupakan bumer terbaik dibanding dengan bumer lainnya.
Hasil perhitungan dari tabel 1 menunjukkan hasil yang scsuai dengan pengujian yang telah dilakukan yaitu burner diameter $12,8 \mathrm{~mm}$ memerlukan bahan bakar sebanyak $18,5 \mathrm{ml}$ dan waktu 9 menit untuk mengubah temperatur air hingga mencapai titik didihnya sedangkan pada burner diameter 21 memerlukan bahan bakar $23 \mathrm{ml}$ dan waka 13 menit kemudian pada burner diameter $10 \mathrm{~mm}$ memerlukan bahan bakar sebanyak $19,5 \mathrm{ml}$ dan waktu 13 menit. Maka diameter 12,8 mm lebih efektif karena memerlukan bahan bakar yang sedikit dan waktu yang paling cepat untuk mengubah terroperatur air hingga mencapai titik didihnya.

\section{KESIMPULAN}

Dari hasil penelitian yang telah dilakukan maka diperoleh beberapa kesimpulan sebagai berikut:

1. Temperatur pembakaran tertinggi dicapai pada burner diameter $10 \mathrm{~mm}$ dan diameter $12,8 \mathrm{~mm}$.

2. Waktu pendidihan $500 \mathrm{ml}$ air tercepat dicapai pada burner diameter $12,8 \mathrm{~mm}$.

3. Konsumsi bahan bakar burner terkecil dicapai burner diameter $12,8 \mathrm{~mm}$.

\section{DAFTAR PUSTAKA}

Boman, GL., Ragland, K.W., 1998, Combustion Engineering, Singapore, McGraw-Hill Companies

Kerampran, S., Desbordes, D. Veyssiere, B., 2000. Study of The Mechanisms of Flame Acceleration in a Tube of Constant Crass Section, Combust. Sci and Tech, Vol. 158, pp $71-91$.

Norli, Oky, S, 2007, Pengaruh Penambahan Reflektor Terhadap Temperatur Api Yang Dihasilkan Pada Kompor Minyak Tamah Bertekanan Dengan Variasi Bentuk Reflektor Kotak, Bulat dan Melingkar, Jurusan Teknik Mesin Fakultas Teknik, Universitas Muhammadiyah Surakarta.

Prasetyo, Totok., 2003, Karakteristik Pembakaran Methanol, Makalah Pengantar Falsafah Sains, Program Pasca Sarjana, Institut Pertanian Bogor, Bogor. 
Prasetyo, Totok, Effendy,Marwan., 2003, Formulasi Tinngi Nyala Bahan Bakar LPG Didaenah Stabilatas Nyala, Jumal Teknik Gelagar, Vol 14 No 01, hal 73-79.

Sutrasno, K, 2009, Methanol, Universitas indonesia, pp 25-38.

Sudarno, 2005, Penganuh Baris Sirip Pada Reflektor Radiasi Panas Terhadap Peningkatan Efesiensi Kompor Minyak Tanah Bersumbu, Seminar Nasional Teknik Elektro Universitas Muhammadiyah Yogyakarta.

Subroto.,2009, Pengaruh Penambahan Kecepatan Udara Terhadap Karakteristik Pembakaran Tungka Batubara, Prosiding Simposium Nasional RAPIVII ISSN:1412-9612 Fakultas Teknik Universitas Muhammadiyah Surakarta. hal M90-M95. 